\title{
Liver Transplantation for Hepatocellular Carcinoma
}

\author{
Tokihiko Sawada Keiichi Kubota \\ Second Department of Surgery, Dokkyo University School of Medicine, Tochigi, Japan
}

\section{Key Words}

Hepatocellular carcinoma - Liver transplantation · Milan criteria

\begin{abstract}
Hepatocellular carcinoma (HCC) has been a major reason for liver transplantation (LT). Globally, LT for HCC is performed on the basis of the Milan criteria, and if performed within those criteria, then the outcome is not different from that of LT performed for other primary diseases. On the other hand, the scope of the Milan criteria covers only early-stage HCC, and many HCC patients do not meet the criteria even at the time of diagnosis. Therefore, over the last decade, efforts have been made to perform LT for patients whose clinical characteristics lie outside the Milan criteria. In Japan, more than $99 \%$ of LTs are living donor LTs (LDLTs) and more than $15 \%$ of LTs are performed in patients with HCC. The 1- and 3-year actual survival rates of LDLT for HCC in Japan are 82 and $79 \%$, respectively. Efforts to extend the Milan criteria have also been made in Japan. To improve the outcome of LT for HCC, pre- and postoperative management of hepatitis $B$ and hepatitis $C$, and immunosuppressant specific for this type of LT are still crucial issues. In this review, we provide an overview of current outcome, efforts to extend the Milan criteria, control of viral hepatitis, and immunosuppression for LT in patients with HCC.

Copyright $\odot 2007$ S. Karger AG, Basel
\end{abstract}

\section{Introduction}

Because of the shortage of donor organs and the need for sustained immunosuppression after transplantation, as therapy for malignant disease transplantation is contraindicated for most organs other than the liver. It is not surprising that liver transplantation (LT) can be regarded as an optimal therapeutic modality for hepatocellular carcinoma (HCC), because, as well as radically removing the whole tumor, LT also replaces cirrhotic liver with healthy liver. Until recently, however, the outcome of LT for HCC remained poor.

Only experimental LTs were studied using animal models before 1960. Starzl and Putnam [1] were the first to attempt human LT in 1963, but the first successful LT was not achieved until 1967. From the dawn of clinical LT, HCC was a major target for LT, but accumulated evidence indicated that although LT gave good results in the short term, cancer recurred in the vast majority of patients within 2 years [2]. Over the following two decades, the outcome of LT improved dramatically, and in 1983 the National Institutes of Health approved LT as a valid therapy for end-stage liver disease. However, the outcome of LT for HCC still remained poor, with a 5-year survival rate of only $18 \%$ [3], until the Milan criteria were proposed in 1996 [4].

\section{KARGER \\ Fax +4161306 1234 E-Mail karger@karger.ch} www.karger.com (c) 2007 S. Karger AG, Basel 0253-4886/07/0242-0126\$23.50/0 www.karger.com/dsu
Tokihiko Sawada

Second Department of Surgery, Dokkyo University School of Medicine

Kitakobayashi 880, Mibu, Shimotsuga

Tochigi 321-0293 (Japan)

Tel. +81 28286 1111, Fax +81 28286 6317, E-Mail tsawada@dokkyomed.ac.jp 
Table 1. Actual survival rate after LT

\begin{tabular}{lcccc}
\hline \multirow{2}{*}{ Reference } & \multicolumn{4}{c}{ Survival rate, \%, at } \\
\cline { 2 - 5 } & 1 year & 3 years & 4 years & 5 years \\
\hline Mazzaferro et al. [4] & & & & \\
$\quad$ Milan & - & - & 85 & - \\
$\quad$ Exceeding Milan & - & - & 50 & - \\
Zavaglia et al. [5] & & & & \\
$\quad$ Milan & - & 76 & - & 74 \\
$\quad$ Exceeding Milan & - & 73 & - & 55 \\
Llovet et al. [6] & & & & \\
$\quad$ Milan & 82 & 69 & - & 69 \\
$\quad$ Exceeding Milan & - & - & - & - \\
Todo et al. [8] & & & & - \\
$\quad$ Milan & 81 & 79 & - & - \\
$\quad$ Exceeding Milan & 75 & 60 & - & - \\
\hline
\end{tabular}

After 1996, many countries adopted the Milan criteria for LT, and outcomes subsequently improved. As the Milan criteria are based on cadaveric LT, there has been some concern about applying the criteria to living donor LT (LDLT). In the meantime, there have been efforts to perform LT in patients whose clinical characteristics lie outside the Milan criteria.

In this review, we provide an overview of the current status and problems of LT for HCC in Japan, and also worldwide.

\section{Milan Criteria}

In 1996, Mazzaferro et al. [4] reported their experience with LT for HCCs. In their series, the outcome of LT in patients with HCC who fulfilled the Milan criteria (a single tumor $\leq 5 \mathrm{~cm}$ or not more than 3 lesions, none exceeding $3 \mathrm{~cm}$ in greatest diameter, without portal invasion and distant metastases) was not different from that of patients without HCC. The 4 -year and recurrence-free survival rates in patients who fulfilled and did not fulfill the Milan criteria were 85 and $92 \%$, and 50 and 59\%, respectively. Recent studies have reported 5 -year survival rates of $70-80 \%$ and recurrence rates of about $10 \%[5,6]$. Actual and recurrence-free survival rates are shown in tables 1 and 2 .

In the United States, the Organ Procurement and Transplantation Network (OPTN) adopted and modified the Milan criteria, and currently only patients who meet the modified criteria (1 lesion 2-5 cm, or 2-3 lesions each
Table 2. Recurrence-free survival rate after LT

\begin{tabular}{|c|c|c|c|c|}
\hline \multirow[t]{2}{*}{ Reference } & \multicolumn{4}{|c|}{ Recurrence-free survival rate, $\%$, at } \\
\hline & 1 year & 3 years & 4 years & 5 years \\
\hline \multicolumn{5}{|l|}{ Mazzaferro et al. [4] } \\
\hline Milan & - & - & 92 & - \\
\hline Exceeding Milan & - & - & 59 & - \\
\hline \multicolumn{5}{|l|}{ Zavaglia et al. [5] } \\
\hline Milan & 95 & 92 & - & 91 \\
\hline Exceeding Milan & - & - & - & - \\
\hline \multicolumn{5}{|l|}{ Llovet et al. [6] } \\
\hline Milan & 100 & 99 & - & 98 \\
\hline Exceedig Milan & - & - & - & - \\
\hline \multicolumn{5}{|l|}{ Todo et al. [8] } \\
\hline Milan & 82 & 79 & - & - \\
\hline Exceeding Milan & 65 & 53 & - & - \\
\hline
\end{tabular}

$\leq 3 \mathrm{~cm}$ ) are enrolled on the waiting list. Enrolled patients are allocated a Model of End-stage Liver Disease (MELD) score and prioritized on the LT waiting list. The MELD score is a numerical score ranging from 6 to 40, and indicates how urgently a patient should undergo LT within the next 3 months. The MELD score is calculated from the serum bilirubin level, prothrombin time international normalized ratio, and serum creatinine level [7].

LDLT is by far the major LT procedure in Japan, where the Milan criteria have also been adopted. Large-scale clinical outcomes of LDLTs for HCCs were reported by Todo et al. [8] in 2004. In their report, the overall 1- and 3 -year patient survival rates were 78.1 and $69.0 \%$, respectively. The 3-year survival and disease-free survival rates in patients with HCC who fulfilled the Milan criteria were 78.7 and $79.1 \%$, respectively, and those of patients who did not fulfill the criteria were 60.4 and $52.6 \%$, respectively (fig. 1). Forty of 316 patients (13\%) developed HCC recurrence. Multivariate analyses indicated that the pretransplant serum AFP level $(>20 \mathrm{ng} / \mathrm{ml})$, tumor size $(>2 \mathrm{~cm})$, portal invasion, and bilobar tumor distribution were independent risk factors for recurrence [8]. Of the 316 patients, 138 (43.7\%) fulfilled the Milan criteria and $171(54.1 \%)$ did not.

\section{Current Status of LT in Japan}

The Japanese Liver Transplantation Society [9] released data on the outcome of LT for HCC in 2005. By December 2004, 3,246 LTs had been performed at 52 transplant cen- 


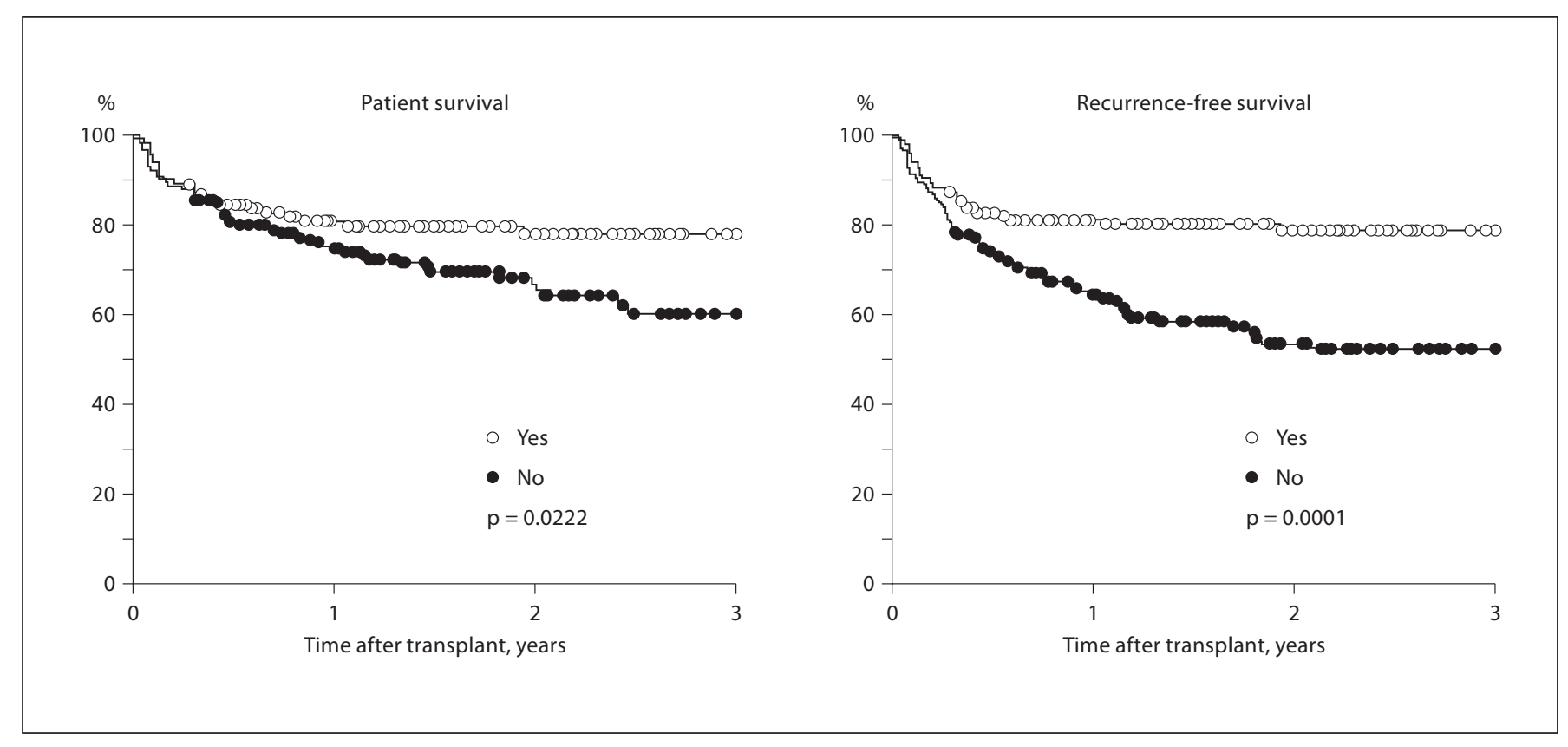

Fig. 1. Patient and recurrence-free survival in relation to the Milan criteria. From Todo et al. [8].

ters in Japan. Among these cases, 3,218 (99.1\%) were LDLTs. The 5-year survival rates of grafts from cadaveric and living donors were 80.4 and $75.0 \%$, respectively. LDLT for neoplastic diseases was performed in 520 cases $(16.6 \%)$, of which 479 (92.1\%) were HCCs. Other neoplastic diseases included hepatoblastoma (18 cases), metastatic liver disease (10 cases), hemangioma (7 cases), and others (6 cases). The overall 5 -year survival rate was $65.7 \%$, which was not significantly different from that of patients who underwent LT for other primary diseases.

LDLT is usually performed between family members and there have always been concerns about whether the Milan criteria can be an accurate indicator for LDLT. From January 2004, LT for end-stage liver disease in adults was approved by the government-based health insurance system in Japan, and patients with HCC associated with end-stage liver disease were considered eligible for LT covered by the health insurance system only if they met the Milan criteria. In the current system, whether patients fulfill the Milan criteria is judged by postoperative pathologic evaluation. Basically, if this reveals that a recipient with HCC does not fulfill the Milan criteria, then the patient and the transplant center are not reimbursed with the total cost of LDLT. This particular environment is a significant obstacle to extending the Milan criteria in Japan.

\section{Extending the Milan Criteria}

Because the Milan criteria limit the use of LT only to patients at a relatively early stage of HCC, many patients are denied the chance of LT even at the time of diagnosis. Currently, efforts are being made to perform LT for HCC patients who exceed the Milan criteria. At the World Transplant Congress held in Boston in 2006, there were 16 reports of studies that had tried to expand the indications of LT beyond the Milan criteria. There are two major options for expanding the criteria, one of which is simply to perform LT for patients who would normally be excluded. Tamura et al. [10] reported that they performed LDLT for patients with up to 5 HCC nodules with a maximum diameter of $5 \mathrm{~cm}$ (the so-called '5-5 rule'). The 3-year recurrence-free survival rates in patients who satisfied and did not satisfy the 5-5-rule were 94 and $50 \%$, respectively [10]. The rate for patients who satisfied the rule was comparable to that of patients who fulfilled the Milan criteria. Gondolesi et al. [11] performed LT for 12 patients with HCCs larger than $5 \mathrm{~cm}$ in diameter, and used adjuvant chemotherapy consisting of doxorubicin. The 2-year survival and recurrence-free survival rates were 60 and $74 \%$, respectively, which were not different from those of patients whose tumors were less than $5 \mathrm{~cm}$ in diameter [11]. These two studies were limited by the 
small number of cases and the short-term observation period.

The other way to perform LT for patients who do not fulfill the Milan criteria is to down-stage HCC preoperatively by locoregional therapy. However, the use of locoregional therapies, such as transarterial chemoembolization (TACE) and radiofrequency ablation, before LT is still controversial. Gadano et al. [12] performed TACE in 77 patients with unresectable HCC, and 13 patients responded to such a degree that they fulfilled the Milan criteria. The recurrence-free survival rate of these patients at a mean follow-up point of 38.7 months was $61.5 \%$, which was significantly lower than that of patients who satisfied the Milan criteria at initial presentation $(87.5 \%)$ [12]. Otto et al. [13] performed TACE in HCC patients who exceeded the Milan criteria prior to LT. Patients who responded to TACE, with a $30 \%$ decrease in the sum of the largest diameter of tumor nodules, showed a 5-year recurrence-free survival rate of $74.5 \%$, which was not significantly different from that of patients who did fulfill the Milan criteria. The recurrence-free survival rate for patients who showed no or a minimal response to TACE was significantly lower (35.4\%) [13]. Thus TACE might be useful not only for down-staging HCC but also for evaluating the biological criteria of HCC in relation to LT [14].

Chen et al. [15] reported the clinical results of radiofrequency ablation for patients with HCCs. They successfully ablated HCCs in $90-95 \%$ of cases, the local recurrence rate was $5-10 \%$, and the 3 -year survival rate was $62-68 \%$. Because these outcomes were not different from that of LT, pretransplant tumor ablation will be a promising tool for down-staging HCCs.

\section{Infections}

According to the report by the Japanese Liver Transplant Society (JLTS) in 2005 [9], the 480 patients who underwent LTs included 160 with HBV- and 277 with $\mathrm{HCV}$-associated chronic hepatopathy. Control of HBV and $\mathrm{HCV}$ is a crucial issue for successful LT.

For patients with HBV, the recent induction of antiviral prophylaxis, lamivudine, and HBV immunoglobulin (HBIg) has significantly improved the outcome of LT. Prevention of graft re-infection can be achieved by injection of high-dose HBIg during the anhepatic phase, with repeated injections during the early postoperative period. However, prophylaxis with HBIg is not effective for patients who are HbeAg-positive at the time of transplanta- tion. In these patients, serum HBsAg reportedly became positive in the first 6 months and was sustained. Lamivudine provides effective prophylaxis for HBIg; it can lower the serum HB titer before LT, and continuous intake can maintain viral inhibition after LT. Patients with lamivudine-resistant HBV are currently treated with adenovir [16] and tenofovir [17].

Prevention of recurrent HCV hepatitis after LT is more difficult than prevention of HBV hepatitis. Most recipients who are HCV-positive preoperatively suffer recurrence of HCV hepatitis after LT, and such a recurrence is more frequent in LDLT than in cadaveric LT [18]. Although treatment for recurrent $\mathrm{HCV}$ hepatitis using pegylated interferon and ribavirin is effective, tolerance to the regimen is very poor because of the side effects, such as fatigue and pancytopenia [19]. The JLTS report indicated that the graft survival rate was similar between recipients with and without HCV infection, and that HCV genotype 1a may be a risk factor for graft loss [20]. Prevention of recurrent $\mathrm{HCV}$ hepatitis after LT remains an important issue.

\section{Immunosuppression}

Most Japanese liver transplant centers use a conventional immunosuppressive regimen for HCC patients undergoing LT, consisting of steroid, cyclosporine or tacrolimus, and mycophenol mofetil. Because rapamycin (sirolimus), a mTOR inhibitor, has not only an immunosuppressive but also an antineoplastic effect, an immunosuppressive regimen containing rapamycin is a rational regimen for patients undergoing LT for HCC. Furthermore, Toso et al. [21] have reported that a regimen including rapamycin improved the 4 -year recurrence-free survival rate in patients who exceeded the Milan criteria (66.8\%).

Currently, rapamycin is not available in Japan and most Japanese liver transplant centers do not use an immunosuppressive regimen specific for HCC. Therefore it is expected that a rapamycin regimen will be tested in Japan in the coming decade.

\section{Concluding Remarks}

The liver is the only organ for which primary carcinoma is a major indication for organ transplantation. The shortage of donor livers has limited the allocation of grafts to recipients who do not fulfill the Milan criteria. 
LDLT is usually a gift of life from blood relatives or family members to affected patients. Fathers, mothers, brothers, sisters, husbands, and wives may wish to donate part of their liver to a loved one, and LDLT is not restricted by the organ transplantation law in Japan. Thus, it is antici- pated that the environment of LDLT will provide a breakthrough for performing LT over the limitation of Milan criteria. It will be likely to start LT using new indication for LT for HCC in Japan where most LT are performed between blood connections.

\section{References}

1 Starzl TE, Putnam CW: Experience in Hepatic Transplantation. Philadelphia, Saunders, 1969.

2 Iwatsuki S, Klintmalm GBG, Starzl TE: Total hepatectomy and liver replacement (orthotopic liver transplantation) for primary hepatic malignancy. World J Surg 1982;6:8185.

-3 Penn I: Hepatic transplantation for primary and metastasis cancers of the liver. Surgery 1991;110:726-735.

-4 Mazzaferro V, Regalia E, Doci R, Andreola S, Pulvirenti A, Bozzetti F, Montalto F, Ammatuna M, Morabito A, Gennari L: Liver transplantation for the treatment of small hepatocellularcarcinomasin patients with cirrhosis. N Engl J Med 1996;334:693-699.

$\checkmark 5$ Zavaglia C, De Carlis L, Alberti AB, Minola E, Belli LS, Slim AO, Airoldi A, Giacomoni A, Rondinara G, Tinelli C, Forti D, Pinzello G: Predictors of long-term survival after liver transplantation for hepatocellular carcinoma. Am J Gastroenterol 2005;100:27082716.

6 6 Llovet JM, Fuster J, Bruix J: Intention-totreat analysis of surgical treatment for early hepatocellular carcinoma: resection versus transplantation. Hepatology 1999;30:14341439.

7 http://www.unos.org/resources/MeldPeldCalculator.asp?index $=98$.

-8 Todo S, Furukawa H; on behalf of the Japanese Study Group on Organ Transplantation: Living donor liver transplantation for adult patients with hepatocellular carcinoma. Experience in Japan. Ann Surg 2004; 240:451-461.

9 http://jlts.umin.ac.jp/Registry(2005).pdf.
10 Tamura S, Sugawara Y, Kaneko J, Kishi Y, Akamatsu N, Yamashiki N, Kokudo N, Makuuchi M: Live donor liver transplantation for hepatocellular carcinoma (abstract 832). Am J Transplant 2006;6(suppl 2):348.

11 Gondolesi GE, Roayadie S, Munňoz L, KimSchuger L, Schiano T, Fishbein TM, Emre S, Miller CM, Schwartz ME: Adult living donor liver transplantation for patients with hepatocellular carcinoma. Extending UNOS priority criteria. Ann Surg 2004;239:142-149.

12 Gadano A, Galdame O, Monaco RG, Villamil A, Bandi JC, Casciato P, Mullen E, Gallo G, Ardiles V, Pekolj J, Mattera J, Ciardullo M, de Santibanes E: Rescue of patients with unresectable hepatocellular carcinoma with pre-transplant transarterial chemoembolization is associated with increased posttransplant recurrence (abstract 2787). Am J Transplant 2006;6(suppl 2):974.

13 Otto G, Herber S, Heise M, Lohse AW, Monch C, Bittinger F, Hoppe-Lotichius M, Schuchmann M, Victor A, Pitton M: Response to transarterial chemoembolization as a biological selection criterion for liver transplantation for hepatocellular carcinoma. Liver Transpl 2006;12:1260-1267.

14 Otto G, Heise M, Moench C, Herber S, Bittinger F, Schuchmann M, Pitton M: Liver transplantation for hepatocellular carcinoma: response to transarterial chemoembolization as a biological selection criterion (abstract 2776). Am J Transplant 2006;6(suppl 2):970.

15 Chen, MShan, Jin-Qing LMD, Yun Z, RongPing G, Hui-Hong L, Ya-Qi Z, Xiao-Jun L, Wan YL: A prospective randomized trial comparing percutaneous local ablative therapy and partial hepatectomy for small hepatocellular carcinoma. Ann Surg 2006;243: 321-328.
6 Perrillo R, Hann HW, Mutimer D, Willems B, Leung N, Lee WM, Moorat A, Gardner S, Woessner M, Bourne E, Brosgart CL, Schiff E: Adenovir dipivoxil added to ongoing lamivudine in chronic hepatitis $B$ with YMDD mutant hepatitis B virus. Gastroenterology 2004;126:343-347.

17 Neff GW, Nery J, Lau DT, O’Brien CB, Duncan R, Shire NJ, Ruiz P, Nery C, Montalbano M, Muslu H, Safdar K, Schiff ER, Tzakis AG, Madariaga JR: Tenofovir therapy for lamivudine resistance following liver transplantation. Ann Phamacother 2004;38:19992004.

18 Garcia-Retortillo M, Forns X, Llovet JM, Navasa M, Feliu A, Massaguer A, Bruguera M, Fuster J, Garcia-Valdecasas JC, Rimola A: Hepatitis $C$ recurrence is more severe after living donor compared to cadaveric liver transplantation. Hepatology 2004;40:699707.

19 Verna EC, Gaglio PJ, Dove LM, Kinkhabwala M, Emond JC, Brow RS: Efficacy and safety of prolonged interferon and ribavirin for recurrent hepatitis $\mathrm{C}$ following orthotopic liver transplantation (abstract 1408). Am J Transplant 2006;6(suppl 2):540.

20 Yagci G, Fernandez LA, Knechtle SJ, D’Alessandro AM, Chin LT, Musat AI, Lucey MR, Said A, Pirsch JD, Kalayoglu M: Longterm outcome of liver transplantation for hepatitis C: factors predicting graft loss and mortality (abstract 1406). Am J Transplant 2006;6(suppl 2):539.

21 Toso C, Meeberg GA, Bigam DL, Ma MM, Wong WWS, Mason AL, Oberholzer J, Shapiro JAM: De novo sirolimus-based immunosuppression after liver transplantation for hepatocellular carcinoma: long-term outcome and side-effects (abstract 1939). Am J Transplant 2006;6(suppl 2):712. 